\title{
Impact of chirality on drug action
}

\author{
Sangita and S. Ray ${ }^{*}$ \\ Division of Medicinal Chemistry, Central Drug Research Institute, Lucknow-226 001, Uttar Pradesh India \\ E-mail : suprabhatray@yahoo.co.in \\ Manuscript received 30 December 2004. revised 26 September 2005, accepted 28 December 2005
}

\begin{abstract}
The biological activity of a drug molecule is usually initiated through its interaction with receptors. The effect induced by the drug depends upon the affinity of the drug molecule for its specific receptor. For chiral receptors such as receptor proteins, the chirality of the interacting molecule plays a major role in defining biological activity towards affinity of the molecule for the receptor and subsequent drug action. The biological activity of a racemate in most cases is the contribution of an active enantioner whereas the other enantiomer may be an undesired commodity.
\end{abstract}

In some cases different enantiomers may possess different activities. Therefore, a recent trend in drug development is the use of the active enantiomer as a drug to avoid unnecessary loading the body with the inactive or undesirable ingredient. To meet this requirement, newer technologies have been developed for chiral separation of molecules.

Keywords : Chirality, drug action, receptor, review.

\section{Introduction}

A drug molecule is a substance which usually acts. through its interaction with specific receptors to alter the biochemical process in the body.

The chirality of a drug molecule refers to the presence of one or more asymmetric carbon atoms giving rise to different molecular configurations $\left(2^{n}\right.$ where $n$ denotes number of asymmetric carbon) depending upon the number of such carbon atoms. Although chirals have exactly the same chemical formula, in three dimensions, there are subtle differences in their molecular projection, which make them differ in producing biological responses.

Louis Pasteur ${ }^{1}$, who made the following observation, realized the importance of chirality long ago in $\mathbf{1 8 6 0 .}$

"All artificial bodies and all minerals have superposable images. Opposed to these are nearly all organic substances, which play an important role in plant and animal life. These are asymmetric, and indeed have the kind of asymmetry in which the image is not superposable with the object."

The role of chirality in drug action became more and more obvious with the discovery of large number of biologically active chiral molecules ${ }^{2}$.

It is well-known that many biological molecules are asymmetric (or chiral), i.e. that they contain atoms in one of the two possible spatial configurations, which are mirror images of each other. Amino acids, carbohydrates, and lipids as well as many other natural and artificıal receptor ligands are chiral ${ }^{3,4}$.

The best examples of chiral molecules are the 20 naturally occurring amino acids, which are $d$-amino acids, socalled because they rotate plane polarized light to the right, and not $l$-amino acids (the $l$-form rotates plane-polarized light to the left). Many biochemical processes and phenomena are stereospecific . For instance, $L$ - and D-enantiomers of amino acids have different tastes ${ }^{45}$, enantiomers of some compounds have different odors ${ }^{67}$, many medicinal preparations have physiological properties different from those of their enantiomers ${ }^{8,9}$, many insecticides are stereospecific $^{10}$, etc.

Enzymes, receptors and other biological molecules, recognize the $d$-amino acids whereas the $l$-forms would be rejected in the same reactions Nevertheless, this distinction can be exploited therapeutically ${ }^{11}$. For example, a peptide consisting of $d$-amino acids will be degraded by proteolytic enzymes, whereas the very same peptıde made up of the $l$ amino acids will resist degradation and therefore have a longer half-iife in the blood stream.

Another group of biologically active chiral compounds found in nature are the steroidal hormones such as estradiol, progesterone, cortisone, testosterone, etc. which contain a number of asymmetric carbon atoms and are usually dextro rotatory. How the chirality of biologically active compounds is related to drug action is discussed here. 


\section{Chiral drug}

It was Louis Pasteur who first discovered chiral molecules when he separated the enantiomers of tartaric acid, which is composed of crystals found at the bottom of wine barrels. To this day not many people knew that these "mirror images" hold different chemical properties while having the same physical properties, except for the direction of rotation of polarized light ${ }^{11-13}$. The majority of naturally occurring chiral molecules used for medicinal purposes are found in nature and consequently sold as the single enantio$\mathrm{mer}^{14-16}$. In contrast, synthesized chiral drugs are generally sold as racemates, this practice is however, quickly changing. There is an increase in the desire for enantiomeric purity in synthesized drugs because many times the distomer, the isomer that does not produce the desired biological effect, can in fact not only be of no use but can also have bad side effects ${ }^{12,13}$.

\section{General features of receptors and receptor sites}

Receptors are generally proteins in nature. There are other classes of receptors as well such as nucleic acid receptors. Structural complimentarity of the drug molecule to the binding site of the receptor, favors binding of the drug to the receptor, thereby initiating biological response through various stages. Detailed discussion of various receptors is beyond the scope of this review. However, features related to the role of molecular chirality are discussed here.

The first important step in drug action is the binding of the drug to the receptor. It is assumed that at least some of the conformational states available to each drug fit into the common receptor site, if the molecules are very similar and their conformational flexibility is not too large. Simple inspection of the structures may provide useful information ${ }^{17,18}$. Identification of the alpha and beta faces of steroids came in this way ${ }^{19}$. Certain important geometric features of drug molecules ${ }^{20}$, crucial distances, angles, and optical handedness are recognized by the receptor. This combination of geometric features is taken to be the lowest common denominator of a class of molecules with similar biological activities, which is termed as "pharmacophore"

Binding sites are found at cervices or grooves in the macromolecular surface. There are both geometric (steric) and chemical complementarities between the small molecules and its receptor site. The binding sites characterized to date have relatively little geometric flexibility and appear to "select" a narrow range of "preferred" conformations of the small molecule from the relatively wide spectrum of conformations that the small molecule can assume in solution. Small molecules that do not fit perfectly into a binding site can still exhibit partial biological activity, but they typically show smaller binding constants and if coupled to enzymatic reactions, slower turnover rate.

\section{Receptor binding}

Most drugs work by binding to receptor molecules-proteins on the cell surface or enzymes. Pharmacophores, functional groups on the drug molecule, have the correct shape to fit into active sites on the receptor molecule and bind with functional groups on the receptor molecule.

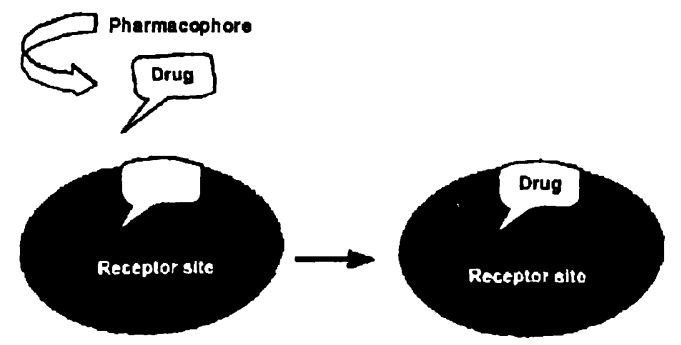

By comparing the structures of drugs with similar pharmacological activity, the pharmacophore can be identified e.g. both Cisplatin 22 and Carboplatin can be used in the treatment of tumours. The group $\operatorname{Pt}\left(\mathrm{H}_{3} \mathrm{~N}\right)_{2}$ is the most likely pharmacophore as it is common to both molecules.

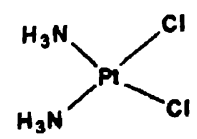

Cisplatin

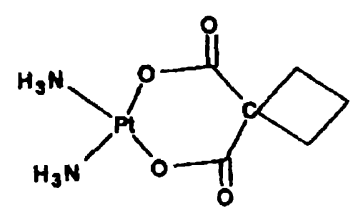

Carboplatin
There are two types of drug molecules: Agonists and Antagonists. Agonists are drugs, which produce a response when they bind to the receptor. Antagonists are drugs, which bind to the receptor but do not produce a response. They, therefore, block the receptor preventing the binding of an agonist. A consideration of the role played by agonists and antagonists in nerve cells should make this clearer.

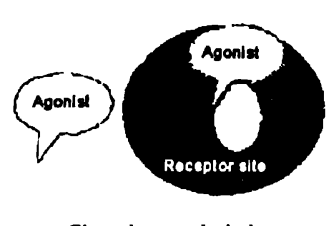

Gives pharmacological respones

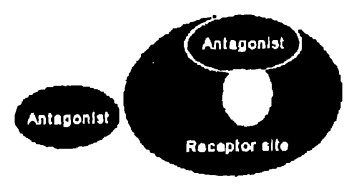

Gives NO pharmacological respones
Acetylcholine is a natural agonist, which causes a signal to pass along a nerve. The agonist fits into grooves and binds to active sites on the receptor molecule.

They mimic the action of the natural agonist and therefore enhance the body's natural response e.g. Methacholine, given to reduce blood pressure, has a similar shape and 
Sangita et al. : Impact of chirality on drug action

pharmacophores as acetylcholine and is therefore able to fit into the receptor and produce a response just like acetylcholine.

Atropine, given to dilate the pupils of the eye, is an acetylcholine antagonist. It is able to bind to the receptor because its shape is similar to acetylcholine.

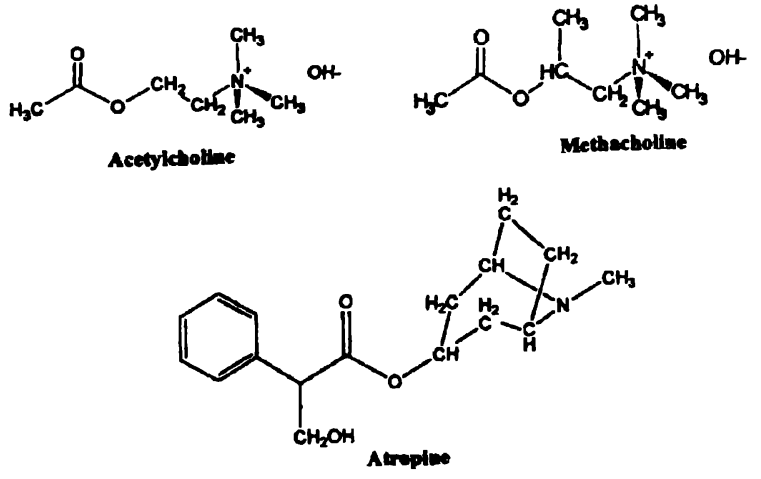

A more common situation encountered is the ligand-receptor binding leding to partial response. In the case of steroid receptors, such as estrogen receptors, there are two activating factors, AF1 and AF2. Whereas AF2 is ligand dependent, $\mathrm{AF} 1$ is independent of ligand binding. Pure antagonistic activity is observed when both $\mathrm{AF} 1$ and $\mathrm{AF} 2$ remain inactivated. Partial activity results in partial agonistic or partial antagonistic activity ${ }^{23}$.

\section{Nature of drug receptor bonds}

All drug molecules interact with biological structures, such as lipoprotein receptors, biomembranes, nucleic acids, or small molecules. This interaction triggers a series of steps that'ultimately results in a macroscopic, physiological change that constitutes the drug effect ${ }^{24}$. A biologic response is produced by the interaction of a drug with a functional or organized group of molecules, which may be called the biologic receptor site. This interaction would be expected to take place by utilizing the same binding forces involved as those when simple molecules interact ${ }^{25}$. These, together with typical exmaples, are collected in Table 1.

Most drugs do not possess functional groups of a type that would lead to ready formation of the strong and essentially irreversible covalent bonds between drug and biologic receptors. In most cases, it is desirable that the drug leaves the receptor site when the concentration decreases in the extra cellular fluids. Therefore, most useful drugs are held to their receptors by ionic or weaker bonds. When relatively long lasting or irreversible effects are desired (e.g. antibacterial, anticancer), drugs that form covalent bonds with the receptor are effective and useful. Consequently, for drugs hydrogen bonds, ionıc bonds, ion-dipole and dipole-dipole interaction and Van der Waals' and hydrophobic forces will carry out acting by virtue of their structural specificity, binding to the receptor site.

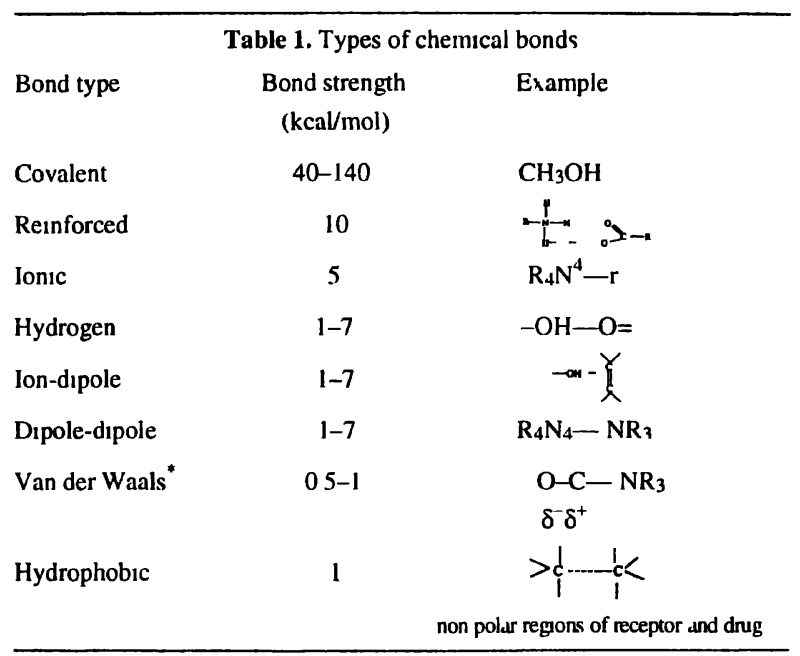

\section{Binding of ligands}

Following factors are desirable for binding of ligands to their respective receptor :

(i) Binding should be structurally specific and stereospecific.

(ii) Binding should be saturable and preferably reversible.

(iii) There should be parallelism between in vivo and in vitro ligand bindng abılity and parallelism in the ability of antagonistic to compete with such binding.

Several factors complicate these requirements. If one assumes that either or both receptor and ligand might be flexible, interpretation of stereospecificity becomes rather complex. It also seems reasonable to expect that different agonists and partial agonists might induce or undergo conformational change to different degrees This would explain why in some series of stereospecific drugs, the ratio of the relative activities of enantiomers is altered, as the structures of these molecules are modified. There is no reason to assume that the stereospecificity of a receptor should not be altered as the results of differential change ${ }^{26}$. It should also be remembered that when stereospecificity is seen, the possibility of stereospecific transport or stereospecific metabolism must be elıminated before it can be concluded that stereospecific attachment to a receptor is taking place. Lack of stereospecificity may also be difficult to interpret. If the binding of the optıcally active ligand is too loose, it could be due to lack of stereospecific receptor.

Pfeiffer's rule ${ }^{27}$ namely that a large difference between 
the activity of enantiomers is related to high affinity holds quite general if the groups on the asymmetric centres contribute to the attachment to active site of the receptor. On the other hand, if the binding of the enantiomeric ligands is very tight, stereospecificity may also be difficult to demonstrate because the kinetics of dissociation may be so slow that for all practical purposes, the ligand may act like an irreversible inhibitor rather than like a reversible inhibitor. This can be a serious problem, when both specific binding and nonspecific binding of the enantiomers are taking place $^{28}$.

\section{The drug-receptor interaction}

A simple model based on the law of mass action or the Langmuir adsorption isotherm ${ }^{29-31}$ as such can represent the processes concerned with the drug-receptor interaction and the induction of a stimulus by the drug. It describes the chance of the molecules of the drug ' $A$ ' have of interacting with the specific receptors ' $R$ '.

$$
[\mathrm{A}]+[\mathrm{R}] \stackrel{K_{1}}{\underset{K_{2}}{\rightleftharpoons}}[\mathrm{RA}] ; \quad K_{2} / K_{1}=K_{\mathrm{A}}
$$

The stimulus induced is supposedly proportional to the quantity of the drug-receptor complex formed or present at a certain moment.

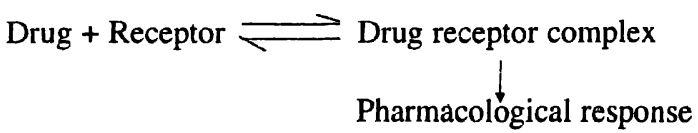

The ideal drug molecule will show favorable binding characteristics to the receptor such that the equilibrium lies to the right. At the same time the drug will be expected to dissociate from the receptor and reenter systemic circulation to be excreted. Major exceptions include the alkylating agents used in cancer chemotherapy and a few inhibitors of the enzyme acetyl cholinesterase. Both of these subclasses of pharmacological agents form covalent bonds with the receptor.

In these cases, the cell must destroy the receptor or in the case of the alkylating agents, the cell would be replaced, identically with a normal cell. In other words, the usual use of drugs in medical treatment calls for the drug effect to last for only a finite period of time. Then, if it is to be repeated. the drug will be administered again. If the patient does not tolerate the drug well, it is even more important that the agent dissociates from the receptor and be excreted from the body.

\section{The molecular basis for drug action}

The effect induced by a drug is the resultant of the interaction between the molecules of the drug and the molecules of which the biological object is composed. The higher the specificity required in the structure of the drug molecule, the more probable it becomes that the effect is based on an interaction of these molecules with certain specific molecules in the biological object. These specific molecules are of the receptors for the drug. They can be defined as those specific molecules, molecule complex or parts of them in the biological object, with which the drug must interact in order to introduce its effect. Drug receptor interaction must be seen as a mutual molding of drug and receptor ${ }^{32,33}$. There is mutual adaptation for the shape and charge distribution that plays an important role in the activation of drug and receptor and therefore is essential to drug action.

\section{Stereochemical basis of drug action}

Most commercial drugs are asymmetric, meaning that they cannot be divided into symmetrical halves. While $d$ and $l$ isomers will have the same physical properties, a large number of drugs are diastereomeric, meaning that have two or more asymmetric centers; diastereomers will have different physical properties. Examples of the diastereomers are ephedrine and pseudoephedrine. Because they interact with optically active, asymmetric biological macromolecules such as proteins, polynucleotides, or glycolipids acting as receptors, it is eminently resonable that many drugs show stereochemical specificity. This means that there is a difference in action between isomers of the same compound, with one isomer showing pharmacological activity while the other is more or less inactive. Therefore, complementarity between an asymmetric drug ${ }^{33,34}$ and its asymmetric receptor is often a criterion of drug activity. The effects of highly active or highly specific drugs depend more upon such complementarity than do those of weakly active drugs. Occasionally, the stereoselectivity of a drug is based on a specific and preferential metabolism of one isomer over the other, or on a biotransformation that selectively removes one isomer ${ }^{35}$. Such stereoselective biotransformations may have far-reaching consequences.

Regardless of the ultimate mechanism by which the drug and the receptor interact, the drug must approach the receptor and fit closely to its surface. Steric factors determined by the stereochemistry of the receptor site surface and that of the drug molecules are, therefore, of primary importance in determining the nature and the efficiency of the drug-receptor interaction. It is evident that a high degree of stereospecificity may be expected for drugs in which a high degree of complementarity for the receptor surface is required for the biological activity ${ }^{36,37}$.

If the ratio of the activity of the optical isomers is plot- 
ted against the activity of all $d l$-forms, it will be found that the larger the latter is, the larger the former will be ${ }^{27}$. A small average dose means a high affinity and thus possibly, a high degree of complementarity to the specific receptors. This is found to be correlated with a large ratio in activity between the isomers, which makes sense. This relationship is known as Pfeiffer's rule. It only holds true if the groups on the asymmetric centre contribute essentially to the drugreceptor interaction ${ }^{38}$. Not only the optical ( $d$ and $l$ ) isomers, but also other stereoisomers may show a difference in biological activity ${ }^{39}$. There are many more examples of cistrns isomers having different biological properties. However, the discussion will be restricted to optical isomers only.

\section{Biological activities of chiral drug}

It is now realized that biological activity of racemic mixtures in most cases rests on one of the two antipodal isomers (enantiomers) and that the other is an undesired commodity. The synthesis of left-handed and right-handed antipodal isomer and their biological testing has led to drugs that are more potent, and more selective in their actions ${ }^{40}$. Many biologically active organic molecules, which occur in nature, including alkaloids and antibiotics, are pure enantiomers, and their biological effects are directly linked to this feature. Synthesis of such molecules, and avoiding chiral technology, leads to racemic mixtures composed of equal amounts of $(S)$ - and $(R)$-enantiomers, which are optically inert. The biological effects are largely confined if optically pure, to only one of the two enantiomers. The other is devoid of such properties ${ }^{16}$.

In case of stereoselectivity in action only one of the component in the mixture, the racemate, is truly active. The biologically more active isomer is termed the eutomer, the less or inactive isomer the distomer. This is so regardless of their $d$ and $l$ or $R$ and $S$ configurations but with regard to a particular biological action. The degree of stereospecificity that is the ratio of the activities (affinities, potencies, etc.) of the enantiomers is termed the eudismic ratio ${ }^{41-43}$. The distomer in the mixture should be regarded as an impurity, or "isomeric ballast" not contributing to the effect aimed at. It, however, potentially contributes to the unwanted effects, the side effects and toxicity. Neglect of the "isomeric ballast", the inactive isomer, constitutes a risk. Its presence implies chemical pollution be it of the environment in general.

The remarkable discrepancy between on one hand the high degree of purity required for pharmaceuticals and on the other hand the acceptance of $50 \%$ impurity as long as isomeric ballast is involved should be a matter of serious concern. Often only one isomer is therapeutically active, the other one which may be therapeutically inactive but could contribute towards side effects. This applies to particularly enantiomers ${ }^{14,15,35.41-51}$ and cis-trans isomers. Many of the products having chiral centres are marketed as racemates $^{52.53}$. However, in most of the cases when it is resolved into enantiomers, great difference in their biological activity is observed ${ }^{40}$.

\section{Examples of distinctly different biological activities of enantiomeric pairs}

Some of the enantiomeric pairs, which show significant different biological activities, are discussed below :

(a) Penicillamine ( $\beta, \beta$-dimethyl cystein/ $\alpha$-amino- $\beta$-mercoptobutyric acid) :

The importance of chirality is well illustrated by penicillamine. Penicillamine is a heavy metal chelator and has been used since 1956 to manage Wilson's disease, a genetic disorder characterized by high tissue copper. Its chelating function also has been employed in mercury, cadmium and lead toxicity problems. Penicillamine also has been used experimentally as an antineoplastic ${ }^{54}$.

Penicillamine has two isomers $S(-)$-penicillamine, and $R(+)$-penicillamine. It is the $S$ isomer that is given to treat Wilson's disease ${ }^{55-57}$, a defect in the body's ability to metabolize copper and cystinuria ${ }^{58.59}$. $S$ isomer is now widely used in rheumatoid arthritis ${ }^{60-62}$. In the case of penicillamine, $R$ isomer would be the distomer and the $S$ isomer would be the eutomer, because it is the isomer that produces the desired biological effect. The pure $\mathrm{D}$ (or $S$ ) form of the drug is used because the $\mathrm{L}$ (or $R$ ) form and the $\mathrm{DL}(R S)$ racemate are much more toxic, as shown by severe adverse reactions such as optic neuritis which can cause blindness.

It is likely that the greater toxicity of L-penicillamine is related to a preferential ability to utilize vitamin $B_{6}$ in an enzyme mediated reaction, such a process might reflect incorporation of L-penicillamine to proteins and thus explain its toxicity. D-Penicillamine could not undergo such a reaction because animal proteins are made up of only L-aminoacids ${ }^{63}$.

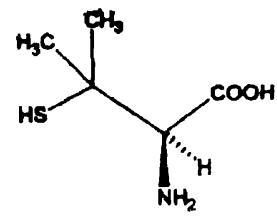

(S)PENICILLAMNE

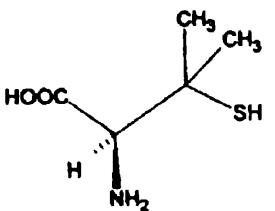

(R) PENICLLLAMINE 
(b) Thalidomide (2-(2,6-dioxo-3-piperidinyl)-1H-isoindole-1,3(2H)-dione)/N-(2,6-dioxo-3-piperidyl)phthalimide :

Thalidomide is one such drug, which created tragic history and is an eye opener suggesting need for chiral separation $^{64, \grave{6} 5}$.

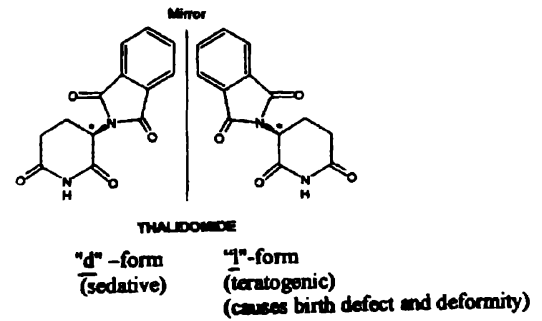

Toxicity and teratogenicity of optical isomers of thalidomide $^{66}$ :

In early 1960's thalidomide was introduced as a tranquillizer in its racemic mixture form. It was particularly effective when given to pregnant women to combat many of the symptoms associated with morning sickness. However, soon it was found that when taken during pregnancy it caused birth malformation and death to babies. The babies who survived, birth defects included deafness, blindness, disfigurement, deft palate, and many other internal disabilities. Toxicity and teratogenicity of the optical antipodes of thalidomide have been studied ${ }^{67,68}$.

There is a striking divergence between the high teratogenic activity ${ }^{69-71}$ of thalidomide and the almost total absence of acute toxicity in whole animals. The drug, which was formerly used therapeutically and continue to be employed as an anti-inflammatory agent is the racemic compound. It is note-worthy that the optical isomers of thalidomide differ considerably in their teratogenic potential (but not in sedative effect), and that they are also acute and more toxic than the racemate. The $R$ form is a safer sedative whereas the $S$ form is responsible for fetal abnormalities and causes severe birth defects and deformities. It interferes with DNA metabolism.

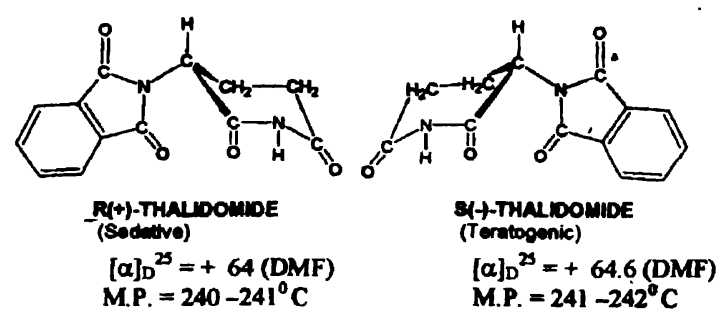

Fig. Optical isomers of thalidomide with absolute configuration and specification.

\section{Other actions of thalidomide :}

There are other biological activities of thalidomide, which have been detected during the extensive experimental investigation of the compound since its introduction is as a therapeutic agent and much more, after the recognition of its teratogenic potential. These are the hyposedative effect $^{72,73}$, neurotoxicity ${ }^{74-77}$, immunosuppressive action ${ }^{78-80}$, anticancer activity ${ }^{81-83}$ and anti-inflammatory ${ }^{84-86}$ action of thalidomide. Although the primary therapeutic use for thalidomide today is in treatment of leprosy, in particular a disease complication called erythema nodosum leprosum, thalidomide appears effective in treating certain cancers.

Anticancer mechanisms includes :

(i) A reduction in inflammatory proteins including tumor necrosis factor alpha,

(ii) Immune system modulation and

(iii) An anti-angiogenesis property, which blocks formation of new blood vessels.

Tumor growth is dependent on angiogenesis. At present, thalidomide is FDA approved only for treatment of leprosy.

(c) Centchroman [trans-1-(2-(4-(7-methoxy-2,2-dimethyl3-phenyl-3,4-dihydro-2H-1-benzopyran-4-yl)-phenoxy)ethyl)pyrrolidine hydrochloride] :

Centchroman is the first nonsteroidal oral contraceptive introduced in the market in its racemic form under the trade names saheli and centron ${ }^{87-90}$.

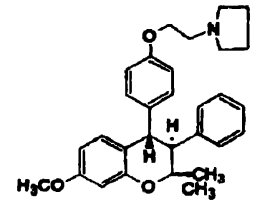

$(38,49)$ or d-CENTCHROMAN (Lewe sectros)

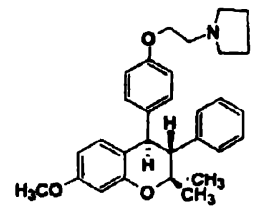

(3R, 4R) or LCENTCHROMAN

(more active)
Centchroman elicits weak estrogen agonistic, potent antagonistic and significant antiimplantation activity ${ }^{91,92}$. It is chiral in nature ${ }^{93}$. Subsequently, centchroman was resolved into its $l$ - and $d$-forms ${ }^{91,94}$. It was found that the biological activity of the compound resides mainly in its $l$-forms as shown in the Table.

\begin{tabular}{|c|c|c|c|c|c|c|}
\hline Compd. & $\begin{array}{l}\text { Dose, } \\
\mu g(\times 3 \\
\text { days })\end{array}$ & $\begin{array}{l}\text { Uterine wet wt, } \\
\text { mean } \pm \text { SEM } \\
\text { (no. of animal) }\end{array}$ & $\begin{array}{l}\% \text { of } \\
\text { control }\end{array}$ & $\begin{array}{l}\text { Relative } \\
\text { uterotrophic } \\
\text { act. }\left(E_{2}\right. \\
=100 \%)\end{array}$ & $\begin{array}{l}\mathrm{RBA}, \%: \\
\text { mean } \pm \mathrm{EM}\end{array}$ & $\begin{array}{l}\text { Antiim- } \\
\text { plant- } \\
\text { ation act. } \\
\text { (MED } \\
\mathrm{mg} / \mathrm{kg} \text { ) }\end{array}$ \\
\hline dl-Entchroman & 5.00 & $29.5 \pm 1.0(16)$ & 174 & 0.56 & $5.24 \pm 1.45$ & 0.25 \\
\hline l-Centchroman & 5.00 & $37.8 \pm 0.9(11)$ & 222 & 1.41 & $15.70 \pm 3.10$ & 0.15 \\
\hline$d$-Centchroman & 5.00 & $16.8 \pm 1.0(5)$ & 99 & - & - & - \\
\hline & 25.00 & $31.8 \pm 2.9(4)$ & 187 & 0.24 & $2.10 \pm 0.90$ & 5.00 \\
\hline
\end{tabular}


The absolute stereochemistry of $l$-centchroman was worked out by X-ray studies. It was found to have $3 R, 4 R$ stereochemistry. This shows that the enantiomer has a methyl group at $\mathrm{C}-2$ in $\alpha$-orientation, similar to $7 \alpha$-position of estradiol and the configuration of the carbon atom C-3 and C-4 matches the configuration of carbons 8 and 9 in estradiol $^{91}$. The 7-methoxy group in centchroman overlays the 3-hydroxy group of estradiol. Thus the $l$-enantiomer has affinity for the receptor and is biologically active. The other enantiomer $d$-centchroman is inactive ${ }^{95}$.

\section{(d) Ephedrine and pseudoephedrine :}

Both are isomeric alkaloids obtained from Ephedra vulgaris var. Helvetica. From the literature it seems probable that the levo-variety is found in the plant when grown in China and pseudoephedrine in the European plant ${ }^{96}$. While L-ephedrine is used as a nasal decongestant the other enantiomer D-pseudoephedrine finds use as a bronchodialator. Ephedrine has two asymmetric carbon atoms and therefore can exists as four possible isomers ${ }^{97-102}$. Isomeric forms include $\mathrm{D}$ and $\mathrm{L}$ ephedrine as well as $\mathrm{D}$ and $\mathrm{L}$ pseudoephedrine with $\mathrm{L}$ ephedrine and $\mathrm{D}$ pseudoephedrine as the naturally occurring isomers ${ }^{103}$.

$\mathrm{D}(-)$ Ephedrine is the isomer most resistant to the development of tachyphylaxis, and $\mathrm{L}(+)$ pseudoephedrine shows the greatest tendency for tachyphylaxis. $L(+)$ Ephedrine displays an intermediate tendency for the development of tachyphylaxis. $\mathrm{D}(-)$ Pseudoephedrine shows only depressor activity $^{101}$.
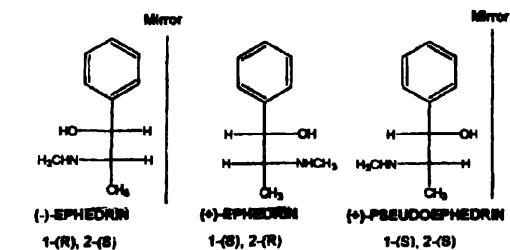

1-(3), 2-(n)
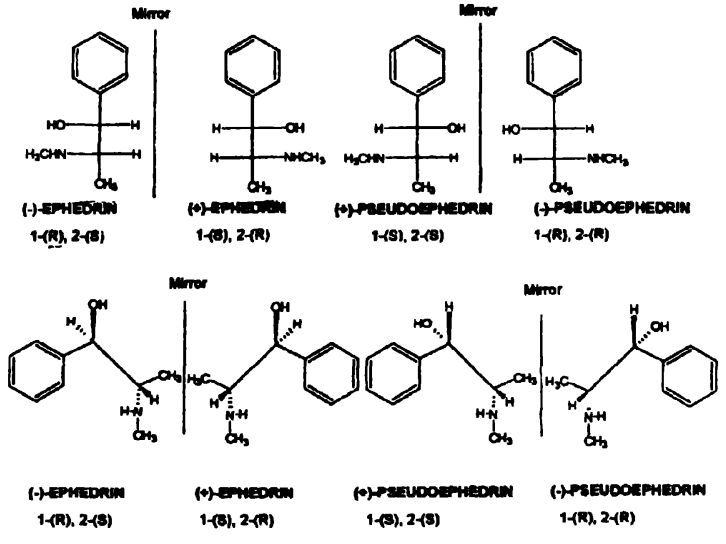

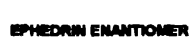

1-(3). 2-(3)

$1-(R), 2-(R)$

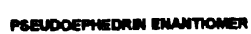

11. Pharmacokinetics and pharmacodynamic properties of chiral drugs ${ }^{104,105}$

Drugs given as racemic mixtures usually have the therapeutic activity residing mainly in one of the enantiomers. The other enantiomer can have undesirable properties, have different therapeutic activities, or be pharmacologically inert $^{16}$. Biological macromolecules are able to distinguish between enantiomeric substrates. A three-point interaction between the drug enantiomers and the macromolecule ${ }^{102}$ can frequently account for this selectivity ${ }^{106,107}$. Significant pharmacodynamic differences between enantiomers are more the rule than the exception. Pharmacokinetic differences between enatiomers are in general, not as great as the pharmacodynamic differences. However, stereoselective protein binding. metabolism and renal clearance are still very important aspects of understanding drug disposition and the time course of drug action.

There may be pharmacokinetic and pharmacodynamic enantiomer-enantiomer interactions ${ }^{107}$.

Consequently, the activity and disposition of a racemic drug may not be the simple sum of the activities and disposition of the individual enantiomers. Enantiomers have been used as sensitive 3-dimensional probes to establish structure-activity relationships, to provide insights into other aspects of drug disposition ${ }^{108-110}$.

A need for a 3-dimensional understanding of pharmacodynamic and pharmacokinetics is implicit in the asymmetric nature of biological environment ${ }^{111}$. Drugs marketed as racemic mixtures is that, in reality, two separate drugs are being given at the same time with different pharmacodynamics and pharmacokinetics. This situation may not be desirable for some racemic mixtures, particularly if therapeutic and unwanted properties reside in different enantiomers. Therefore, it would appear desirable to evaluate the pharmacological properties of each of the enantiomers of a racemic mixture to see if the risk/benefit ratio of the mixture can be improved by use of only one of the enantiomers.

\section{Advantages of using optically pure drugs}

In pharmaceuticals, there are many advantages to manufacturing optically pure drugs. This would mean smaller doses of medication because the medication would contain only the necessary molecule, less side effects because of the elimination of distomers, and drugs that would be twice as active as potent as before ${ }^{39,112,113}$.

\section{Racemic switch}

Due to the advantages of using single isomer as drugs, many of the old products, which were introduced as drugs in their racemate forms, are now being redeveloped in the single enantiomeric form. This approach is known as racemic switch ${ }^{114-118}$.

\section{Biotransformation ${ }^{119-121}$}

The stereoselective biotransformation of a chiral drug can affect its clinical properties. For instance, the anticancer prodrug ifosfamide is metabolized via two pathways, one of 


\section{J. Indian Chem. Soc., Vol. 83, April 2006}

which activates the drug and underlies its cytotoxic properties, and the other, which deactivates the drug and underlies many of its toxic side effects. The stereoselective nature of these two pathways results in the $R$-enantiomer being less toxic than the racemic mixture.

\section{Chiral inversion ${ }^{122-126}$}

Ibuprofen, an anti-inflammatory 2-aryl propionic acid drug, containing both $(S)$ and $(R)$ isomers, the $(S)$ isomer that is the eutomer is 160 times more potent analgesic than $R$ enantiomer in inhibiting prostaglandin synthetase in vitro, however in vivo potency ratio is only $1.4^{127}$. This dramatic difference in potency was explained by stereospecific chiral inversion of the inactive $(R)$ isomer in the body to active (S)-ibuprofen in vivo.

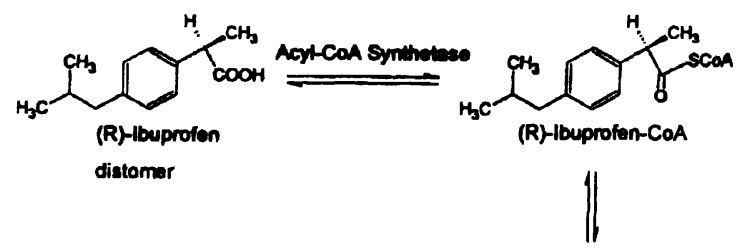

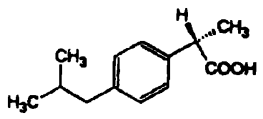

(S)-lbuprofen-CaA outomor
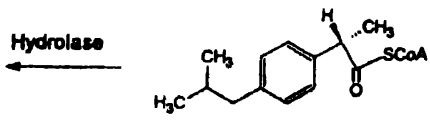

(S)-Ibuprolien-CoA

\section{QSAR for chiral drugs}

Most of the physical as well as chemical properties of chiral molecules are similar. At the same time, it is wellknown that many biological molecules (amino acids, carbohydrates, lipids, many receptor ligands) are chiral and that the chirality plays an essential role in defining biological activity. Drugs containing a mixture of enantiomers over one stereoisomer increases the importance of quantitative structure-activity relations (QSARs) for chiral drugs. To establish the mathematical relations between biological activities of molecules and their physicochemical properties, quantitative structure-activity relationship (QSAR) methods are used. Due to stereospecificity of biological effects, QSAR methods must be capable of taking into account atomic chiralities. Indeed, one of the most popular 3DQSAR methods, Comparative Molecular Field Analysis (CoMFA), developed in mid-1980s ${ }^{128,129}$ and other CoMFA-like methods take into account chirality by default, since molecular fields of chiral isomers are different. However. CoMFA ${ }^{130}$ and many other 3D-QSAR methods have several shortcomings. In quantitative structure-activity relationship (QSAR) studies, taking chirality into account has become possible only after the development of the so-called three-dimensional QSAR methods such as the comparative molecular field analysis (CoMFA) ${ }^{128,129}$. On the other hand, QSAR methods based on descriptors calculated using molecular graphs, i.e. structural formulas of compounds (2DQSAR methods), provide an appealing alternative to 3D$\mathrm{QSAR}^{130.131}$. Despite their computational efficiency, until recently, due to the lack of adequate descriptors 2D-QSAR methods were unable to take chirality into account. The first attempt to add chirality descriptors to conventional 2D (Molconn-Z) descriptors for QSAR studies was reported in $1998^{131}$. 2D-QSAR models that took into account chiral atoms were built for ligands of $D_{2}$ dopamine and $D$ receptors ${ }^{131}$. The $2 \mathrm{D}$ QSAR models appeared to have better statistics and predictive ability than those based on conventional nonchiral descriptors only ${ }^{132}$. Using chirality descriptors, a series of chiral barbiturates were correctly classified as sedatives or stimulants ${ }^{131.132}$.

The application of the chirality descriptors to QSAR studies on a series of ecdysteroid analogues of 20hydroxyecdysone $(20 \mathrm{E})$, the steroid hormone responsible for onset and regulation of molting in almost all arthropods, ${ }^{130,133-134}$ was used in independent CoMFA studies ${ }^{134}$ has been published.

\section{Pharmaceutical products as asymmetric nature}

\begin{tabular}{|c|c|c|}
\hline SI. no. & Drug & Treatment structure \\
\hline 1. & $\begin{array}{l}\text { Formoterol (long-acting } \beta_{2} \\
\text { adrenergic agonist inhalant) }\end{array}$ & $\begin{array}{l}\text { Asthma, emphysema and chronic } \\
\text { obstructive pulmonary disease }\end{array}$ \\
\hline 2. & Oxybutynin & Urinary incontinence \\
\hline 3. & $\begin{array}{l}\text { Doxazosin ( } \alpha \text {, adrenergic } \\
\text { blocking agent) }\end{array}$ & $\begin{array}{l}\text { Benign hyperplasia of the } \\
\text { prostate gland }\end{array}$ \\
\hline 4. & Sibutramine & $\begin{array}{l}\text { Inhibit reuptake of the neuro } \\
\text { transmitter norepinephrine, } \\
\text { serotonin and dopamine at nerve } \\
\text { synapses to treat obesity }\end{array}$ \\
\hline 5. & Cetirizine & Allergic rhinitis (Hay fever) \\
\hline 6. & Ticalopride (Cisapride) & Gastric motility in diabetes patients \\
\hline 7. & $\begin{array}{l}\text { Amlodipine (calcium } \\
\text { channel blocker) }\end{array}$ & High blood pressure \\
\hline 8. & $\begin{array}{l}\text { Ondansetron (serotonin } \\
\text { blocker) }\end{array}$ & $\begin{array}{l}\text { Nausea and vomiting during cancer } \\
\text { chemotherapy }\end{array}$ \\
\hline 9. & Bupropion (wellbutrin) & $\begin{array}{l}\text { Depression, treatment for nicotine } \\
\text { addiction }\end{array}$ \\
\hline 10. & $\begin{array}{l}\text { Zopiclone (espopiclone) } \\
\text { (Imovane and Amoban) }\end{array}$ & Sleeping pill (insomnia) \\
\hline 11. & $\begin{array}{l}\text { Simvastatin (inhibits the } \\
\text { enzyme- } \beta \text {-hydroxy- } \beta \text { - } \\
\text { methylglutaryl coenzyme) }\end{array}$ & Lowering of serum cholesterol \\
\hline 12. & $\begin{array}{l}\text { Ezetimibe (inhibits the } \\
\text { absorption of dietary } \\
\text { cholesterol) }\end{array}$ & Lowering of serum cholesterol \\
\hline 13. & Devazepide (MK-329) & CCK-A-antagonist \\
\hline
\end{tabular}


Table (contd.)

14. Saquinavir
15. Omapatrilat (vasopeptidase
inhibitors)

16. Captopril (Squibb) (ACE inhibitor)

17. Lisinopril (ACE inhibitor)

18. Labetalol ( $\alpha$ and $\beta$ adrenoceptor)

19. Chloramphenical

20. Pioglitazone

21. Rosiglitazone

22. Troglitazone

23. Candoxatril

24. Naproxen

25. Enalapril (ACE inhibitor)

26. Loxiglumide ( $d$ isomer dexloxiglumide) (selective CCK-A receptor antagonist)

27. Lercanidipine (calcium channel blocker)

28. Methyl phenidate (Ritalin)

29. Albuterol/Proventil/Ventolin ( $/$ isomer Levalbuterol) (Xeponex)

30. Cisapride (propulsid)

31. Omeprazole ( $S$ form Esomeprazole) (proton pump inhibitor)

32. Citalopram ( $S$ form Escitalopram) (serotonin reuptake inhibitor)

33. Fluoxetin (prozac) (seretonin Antidepressant reuptake inhibitor)

34. Propanolol ( $\beta$-adrenergic blocking agent)

35. Zafirlukast (leukotriene receptor antagonist)

36. Sibutramine

37 Montelukast (histamine $\mathrm{H}_{2}$ receptor antagonists)

38. Levofloxacin

39. Metoprolol
AIDs virus protease inhibitor (HIV protease inhibitor)

High blood pressure by inhibiting both. Angiotensinconverting enzyme (ACE) and neutral endopeptidase

Blood pressure control (antihypertensive agent)

Antihypertensive agent (blood pressure control)

Hepatotoxic action ( $\beta$ and $\alpha$ adrenergic blocking agent)

Antibiotic

Diabetes

Diabetes

Diabetes

High blood pressure and congestive heart failure

Antiinflammatory, antipyretic, analgesic

Blood pressure control (antihypertensive agent)

Irritable bowel syndrome,

functional

gastrointestinal

disorders, pancreatic cancer. pancreatitis, appetite disorder, abdominal pain .

High blood pressure

Attention deficit disorder or hyperkinetic child syndrome, insomnia and appetite suppression

Asthma

Heart burn caused by gastroesophageal reflux disease

Stomach ulcer

Depression

Depression

High blood pressure

Antihistaminic agent, asthma

Depression, antidepressants and mood-brighteners

Asthma

Treatment of complicated skin and skin structure infections

$\beta$-blocking activity of heart, blocking $\beta_{2}$ receptors in ciliary process

$\begin{aligned} \text { 40. } & \text { Atenolol } \\ \text { 41. } & \text { Esmold } \\ \text { 42. } & \text { Pindolol } \\ 43 . & \text { Acebutolol } \\ 44 . & \text { Nadolol } \\ 45 & \text { Indinavir } \\ 46 & \text { Taxol } \\ 47 . & \text { Levomoprolol } \\ 48 . & \text { Dexfenfluramine } \\ 49 . & \text { Thiorpham }\end{aligned}$

Table (contd)

$\beta$-blocker reduction in heart rate and mean arterial pressure

Hypotensive agents ( $\beta$-blocker)

Cardiac drugs ( $\beta_{1}$ and $\beta_{1}$ blocking receptor)

Cardiac drugs ( $\beta$-blocker)

Cardiac drugs

Antivirals

Antineoplastic agents

$\beta$-blocker

Anti-obesity agents ( $\beta$-Adrenergic blocking agent)

ACE/NEP inhibitor

(Selective-NEP inhibitor)

\section{Conclusion}

Since the enantiomers of a chiral compound may have different pharmacological and other bioreactions, the need for bioevaluation of the enantiomers, instead of the racemate is obvious. This would require adequate availability of the enantiomers in the first instance for evaluation and subsequently for marketing as a drug. A recent trend in preparation of pure enantiomers is the utilization of readily and cheaply available natural products having a chiral centre (s) - the so called chiral pool for stereospecific synthesis of desired enantiomers. But this approach has limitations that the other enantiomer will not be available for ascertaining its pharmacokinetic and other bioreactions. Moreover, inversion of the chiral centre in the biophase is known to occur sometimes ${ }^{135}$, so that study of only one enantiomer is not sufficient to provide a complete picture of the chiral compound. It is, therefore, clear that resolution of racemates will continue to be important, but development of quicker methods, of separation will be necessary.

Enantioseparation ${ }^{136.137}$ of chiral drugs can sometimes be laborious and time-consuming. Getting proper chiral stationary phases are often difficult. Therefore. with all of these practical aspects in mind, it is quite natural to predict the chromatographic behaviors of chiral drugs from its 3-dimensional molecular structure, it would be a very useful tool in evaluating chiral behaviors of drugs. In recent times various methods have been developed using several modes of capillary electrophoresis, including micellar electrokinetic chromatography (MEKC) and electrokinetic chromatography (EKC) for the separation of enantiomers ${ }^{138.139}$.

It is believed that the Gradiflow technology will be the basis for an alternative separation technique of chiral molecules such as ampholytic enantiomers offering significant cost reductions, increased product recoveries and superior purities compared to what is currently used. 
By perfecting the separation, chiral drugs will become safer, cheaper and take less time to bring to market. A new dimension has been recently been added to drug design as a consequence of the growing awareness of the important role of the asymmetric centre in the case of chiral drugs. Hence knowledge of the absolute stereochemistry of the asymmetric centre(s) is a pre-requisite for the development of a chiral compound as drugs.

A major break through in this field has been the development of hollow membranes for large scale separation ${ }^{140}$ This technology has already found application in industry. It is possible that membrane filters may become available for laboratory scale preparation. A chiral adsorbent for preparative thin layer chromatography may be developed, which would be useful for autoradiographic monitoring of the metabolism of chiral compounds. Computer programmes may be developed for selecting the appropriate technology for resolution of a racemate.

Now synthetic techniques, the laboratory synthesis of pure enantiomers have become easier, many drugs currently sold as racemates will soon be available as "chiral drugs" to prevent any possible side effects of the inactive enantiomer. Increasing knowledge of the reactions of the chiral compounds in the biophase suggest that pharmacokinetic studies on chiral candidate drugs should be initiated much earlier, before phase I clinical trials, as is done in the case of non-chiral drugs.

The use of enzymes for one industrial manufacture of chiral drugs should increase since a major advantage would be the reduction of environment pollution. The development of new chiral drugs in the future should be directed to enantiomers capable of bioselective interaction with subset of a receptor family.

Present day experience suggests that the pharmacolog1cal activity of the enantiomers of chiral drugs can follow several distinct patterns. In general, if one enantiomer contains the therapeutıc activity of interest, the second enantiomer may differ functionally in a number of ways. For instance, it may have no discernible pharmacological activity at all. It may possess a therapeutic activity that is simılar to, or alternatıvely one, which is distinct from, that of the first enantiomer. Finally, it may behave as an antagonist to the first enantiomer or possess an undesirable pharmacological actıvity (i.e. toxicity). As a consequence of this diversity, the relative contribution of each enantiomer to a racemic drug's overall pharmacodynamic characteristics, and hence its clinical features, may vary considerably from one drug to the next
Racemic drugs that are currently marketed and reaching marketing were developed when knowledge of drug enantiomers was less sophisticated; a flexible regulatory approach is required. At present, it is probably reasonable to require substantial information on the properties of enantiomers of racemic drugs, but the balance is on the side of regulatory agencies needing to justify, provided adequate information is submitted, requirements for enantiomerically pure drugs.

\section{Acknowledgement}

One of the authors (Sangita), thanks to CSIR, New Delhi (India) for the award of Senior Research Fellowship.

\section{References}

I K Willıams and E Lee, Drugs, 1985, 30, 333

2 H Shindo and J Caldwell, Chirality, 1995, 7, 349

3 V M Potapov, "Stereochemıstry", Khımı, Moscow, 1988

4 J Solms, L Vuataz and R H Egl, Experıentıa, 1965, 21, 692

5 S S Schıffman, T B Clark and Gagon, J Physiol Behav, 1982, 28, 457

6 M Laska and P Teubner, Chem Senses, 1999, 24, 161

7 E H Polak, A M Fombon, C Tilquin and P H Punter, Behav Brain Rer, 1989, 31, 199

8 W H DeCamp, Chnality, 1989, 1, 2

9 A J Hutt and S C Tan, Drug, 1996, 52, 1

10 N Kurihara, J Miyamoto, G D Paulson, B Zeeh, M W Skıdmore, R M Hollıngworth and H A Kuıper, Pure Appl Chem, 1997, 69, 1335

II D Voet and J G Voet, "Biochemistry". 2nd ed, 1995, Vol 64

12 Roger M Lane and Glen B Baker, Cell Mol Neu, 1999, 19, 355

13 S C Stunson, Chem Eng News, 2000, 78, 43

14 B Testa, "Principles of Oiganic Steieochemıstry", Dekker, New York, 1979

15 B Testa, in "Stereochemıstry", ed Ch Tamm, Elsevier Bıomedical Piess, Amsterdam, 1982, p 1

16 D E Drayer, Clin Phaim Ther, 1986, 40, 125

17 H M Lambert Janssen, Boorg Med Chem, 1998, 6, 785

18 A Korolkovas, "Essentıls of Molecular Pharmacology", WileyInterscience, New York, 1970

19 M E Wolff, W Ho and R Kwok, $J$ Med Chem, 1964, 7, 577

20 P Gund, Prog Cell Mol Bıol, 1970, 117

21 P Erhlich, Chem Ber, 1909, 42, 17

22 R J Walker and J P Fawcett, Prog Diug Res, 1993, 41, 5 I

23 Suprabhat Ray, Reema Rastogı and Atul Kumar, Prog Drug Rer, 2002, 59, 202

24 "Medicinal Chemistry - A Biochemical Approach", ed T Nogrady, Oxford University Press, 1985, p 3

25 B G Katzung, "Basıc Principles Introduction in Basic and Clinical Pharmacology", ed B G Katzung, Appleton-Longe, 1998, p 1

H G Mautne1, Pharmacol Rev, 1967, 19, 107

27 C C Pfeiffer, Sc ience, 1956, 124, 29 
Sangita et al. : Impact of chirality on drug action

28. "Burger's Medicinal Chemistry". 4th ed., Part I, "The basis of medicinal chemistry', ed. M. E. Wolff, Chap. 6, 'Drug-Receptor Geometry', Kuntz. I.E. p. 285.

29. A. J. Clark, "General Pharmacology" in : 'Heffter's Hand buch der experimentellen pharmakologie', eds. W. Heubner and T. Erg Schuller, Springer, Berlin, 1973a, Vol. 4.

30. A. J. Clark, "The Mode of Action of Drugs on Cells", eds. Baltimore, Williams and Wilkins, $1937 \mathrm{~b}$.

31. E. J. Ariens and A. M. Simonis, J. Pharm. Pharmacol., 1964, 16 , 137.

32. "Molecular Pharmacology", 'The mode of action of biologically active compound', ed. E. J. Ariens, 1964, 1, Sect. IIA; "Drug Receptor Interaction", 'Interaction of one or more drugs with one receptor system', eds. E. J. Ariens and A. M. Simonis, Incorporation with J. M. van Rossum, p. 119.

33. H. Eyring, L. L. Jones and J. D. Spikes, in "Horizons in Biochemistry", eds. M. Kasha and B. Pullman, Academic Press, New York, p. 229.

34. M. Kenneth Williams, Adv. Pharmacol., 1991, 22, 57.

35. L. R. Low and N. Castagnoli, Annu. Rep. Med. Chem., 1978, 13, 304.

36. A. H. Beckett, Fortschr. Arzne., 1959, 1, 455.

37. A. L. M. Kerremans, Neth. J. Med., 1993, 42, 80.

38. B. W. J. Ellenbroek and J. M. van Rossum, Arch. Intern. Pharmacodynamie, 1960. 125. 216.

39. C. M. Kagawa, F. M. Sturtevant and C. G. van Arman, J. Pharmacol. Expt. Therap., 1959, 126, 123.

40. A. Brossi, Med. Res. Rev., 1994, 14, 665.

41. E. J. Ariens, "Stereoselectivity in Bioactive Agents : General Aspects", in 'Stereochemistry and biological activity of drugs', eds. E. J. Ariens, W. Soudijn and P. B. Timmermans, Blackwell Scientific Publications, Oxford, London, 1983, p. II.

42. B. Testa, P. A. Carrupt, L. Christiansen, P. Christoffersen and M. Reist, Trends Drug Res., 1993, 20, 1.

43. F. Lehmann, "Receptors and Recognition", eds. P. Cuatrecasas and M. Greaves. Chapman and Hall, London, 1978, 5 (series 4), 1.

44. A. H. Beckett and A. F. Casy, J. Pharm. Pharmacol, 1954, 6, 986.

45. M. Simonyi, Med. Res. Rev., 1984, 4, 359.

46. B. Testa, Trends Pharmacol. Sci., 1986, 7, 60.

47. T. Walle and U. K. Walle, Trends Pharmacol. Sci., 1986, 7, 155.

48. M. Eichelbaum, Biochem. Pharmacol., 1988, 37, 93.

49. F. Jamali, R. Mehvar and F. M. Pasutto. J. Pharm. Sci., 1989. 78. 695.

50. G. T. Tucker and M. Lennard, Pharmac. Ther., 1990, 45, 309.

51. E. J. Ariens, Eur. J. Clin. Pharmacol., 1984, 26, 663.

52. E. J. Ariens, E. W. Wuis and E. J. Verigana, Biochem. Pharmacol., 1988, 37, 9.

53. S. Mason, New Sci., 1984, 1393, 10.

54. F. W. Rosa, Teratology, 1986, 33, 127.

55. S. Miyagawa, A. Yoshioka, M. Hatoko, T. Okuchi and K. Sakamoto, Br. J. Dermatol., 1987, 116, 95.

56. G. J. Brewer, Drugs, 1995, 50, 240.

57. E. E. Santos Silva, J. Sarles, J. P. Buts and E. M. Sokal, J. Pediatr.,
1996. 128, 285

58. T. F. Yu, J. Roboz, S. Johnson and C. Kaung, J. Rheumutol., 1984. 11, 467.

59. V. A. R-T. Arzneim-Forsch. (Drug Res.). 1974, 24, 914.

60. H. G. Taylor and A. Samanta. Drug Safety, 1992, 7. 46.

61. H. E. Haward-Lock, C. J. L. Lock. A Mewa and W. F. Kean. Semin. Arthritts Reum.. 1986. 15. 261.

62. V. D. Steen, S. Blair and T. A. Medsger, Ann. Intern. Med., 1986, 104, 699.

63. W. F. Kean, C. J. L. Lock and H. E. Haward-Lock, Lancet, 1991, 338, 1565.

64. W. Hunkeler, Chimica, 1993, 47, 141 .

65. R. Mechoulam, J. J. Feigenbaum, N. Lander, M. Segal. T. U. Jarbe, A. J. Hiltunen and P. Consroe. Experientia, 1988, 44, 762.

66. S. Fabro, 'R. L. Smith and R. T. Williams, Nature, 1967, 215, 296.

67. G. Casini and M. Ferappi, Farmaco. Ed. Sci., 1964, 19, 563.

68. Y. F. Shealy. C. E. Opliger and J. A. Montgomery, Chem. Indust.. 1965. 1030.

69. L. P De Souza, Br. Med. J., 1959, 2, 635.

70. G. Neuhaus and K. Ibe. Med. Klını.. 1960, 55. 544

71. D. M. Burley, Med. World, 1960, 93, 26.

72. R. C. A. Fredrickson, I. H. Slater, W. E. Dusenberry, C. R. Hews, G. T. Jones and R A. Moore. J Pharmacol. Exp. Ther., 1977, 203, 240.

73. K. I. Kaitin. Diss. Abst. Int., 1982, 43, 1811.

74. A. L. Florence, Br. Med. J., 1960, 2. 1954.

75. D. Burley, Br. Med. J., 1961. 1. 130.

76. K. H. Schulz and M. Jänner, Allergic Asthma, 1963. 9, 226.

77. J. Kimming, Verh. Deutsch. Ges. Inn Med.. 1961, 67, 486

78. K. Hellmann, Lancet, 1966. 1, 1136.

79. K. Hellmann, Wien. Med. Wochenschr., 1967, 117, 415.

80. T. Chard, Lancet, 1966, 1. 1373.

81. R. C. Hastings, Ethiop. Med. J., 1980, 18, 65

82. R. C. Hastings, M. J. Morales and E. J Schannon, Pharmacologist, 1976. 18, 569.

83. R. L. Barnhil and A. C. Mc Dougall, J. Am. Acud. Dermatol., 1982, 7, 317.

84. J. M. Miller, M. Ginsberg, G C. Mc Elfatrick and I. L. Shonberg, Antibiot. Med. Clin. Ther., 1960. 7, 743.

85. R. C. Hastings and M. J. Morales. Int. J. Leprosy. 1973, 41, 494.

86. T. Hunziker and A. Krebs. Hautarzt., 1983, 34, 66.

87 V P. Kamboj. S. Ray and B N. Dhawan. Drugs Todav, 1992, 28. 227

88. V. C. Jordan and C. S. Murphy, Endocr. Rev.. 1990. 11, 578.

89. B. J. Furr and V. C Jordan. Pharmacol. Ther., 1984, 25, 127.

90. N. Anand and S. Ray, Ind. J. Exp Bıol., 1977, 15, 1142.

91. M. Salman, S. Ray, N. Anand, A K. Agarwal, M. M. Singh. B. S. Selty and V. P. Kamboj, J. Med. Chem., 1986, 29, 1801.

92. M. M. Singh, Med. Res. Rev., 2001, 21, 302

93. N. Srivastava. S. Ray, I. Dwivedi. S. R. Wilson. R. K. Hom and J. A. Katzenellenbogen, Biorg. Med. Chem. Lett., 1996, 6, 1747.

94. A. Mukhopadhyay, S. Gupta, S. Ray and A. K. Giri, Cancer Lett., 1999, 144. 137. 


\section{J. Indian Chem Soc., Vol. 83, April 2006}

95 S Ray, A Tandon, I Dwivedi, S R Wilson, J P O'Neıl and J A Katzenellenbogen, $J$ Med Chem, 1994, 37, 696

96 K K Chen and C H Kao, J Ain Phaim Assoc, 1926. 15. 625

97 R H F Manske and T B Johnson, J Am Chem Soc, 1929, 51 580, 1906

98 Karl Freudenberg, Eugene Schoeffel and Emıl Bıaun, J Am Chem Soc, 1932, 54, 234

99 K Freudenberg and F Nıkola1, Ann, 1934, 510, 223

100 B Witkop and C M Foltz, J Am Chem Soc, 1957, 79, 197

101 R A Hahn, J B Lapidus, A Tye and J W Nelson, J Pharm Sct, 1965, 54, 378

102 Jules B LaPıdus, Arthur Tye, Popat Patıl and Balakrıshna A Mod, J Med Chem, 1963, 6, 76

103 K Freudenberg, E Schoeffel and E Braun, J Am Chem Soc, 1932, 54, 234

104 Dion R Brocks and Reza Mehvar, Clinical Phaimacohınetics, 2003. 42. 1359

105 Dion R Brocks. Majıd Vakıly and Reza Mehva1, Chuality in Drug Desıgn and Development, 2004, 191

106 R R Ruffolo ( $\left.\mathrm{J}_{1}\right)$, "Stereoselectıvity in Adrenergic Agonists and Adienergic Blockıng Agents", in 'Stereochemistry and biological activity of diugs', eds E J Ariens, W Soudjun and P B Tımmermans, Blackwell Scientıfic Publıctıons, Oxford, 1983, p 103

107 F P Luduena, Aich d'inter Phauma, 1962, 87, 155

108 J K Barton, Science, 1986, 233, 727

109 S K Sengupta, D P Rosenbaum. R K Sehga, B Almassian and J Blondın, J Med Chem, 1988, 31, 1540

110 M S Lennard. G T Tucker, J H Silas and H F Woods Xenobiotica, 198616435

111 Kanneth M Willıams, Clın Exp Phaımacol Physıol. 1989, 16, 465

112 E J Anens, Med Res Rev, 1986, 6. 451

113 Bertıl Waldeck, Chirality, 1993, 5, 350

114 S C Stınson, Chem Eng News, October 1 (2001), 79

115 Jindra Valentova and A J Hutt, Ceska a Slovenska Faımacie, 2004, 53. 285

116 Michael J Cannarsa, Chımıca Oggı, 1999, 17, 28

117 I Szelenyı G Geısslınger, E Polymeropoulos, W Paul, M Herbst and K Bıune. Drug News \& Pel sper tive, 1998, 11, 139

118 S C Stunson. Chem Eng News, October 23 (2000), 55

119 Ramesh N Patel, Adrances in Applied Microbiology, 1997, 43. 91

120 Honote Monti and Geraid Audran, Mini-Reviews in Organic Chemistry, 2005, 2, 265
12. Shaoyı Chen. Xıu Yang and Yujıng Qın, Shengwu Gongcheng Jinzhan, 2000, 20, 60

122 I Tegeder, $\mathrm{K}$ Willıams and $\mathrm{G}$ Geısslınger. "Metabolıc Chual Inversion of 2-Arylpropionic Acids Handbook of Experımental Pharmacology" (Stereochemical Aspects of Drug Action and Disposition), 2003, 153, pp 341-354

123 Andrew J Hutt and John Caldwell. Jouınal of Pharmacy and Phaımacology, 1983, 35, 693

124 Neal M Davies, Chı alıty ın Diug Desıgn and Development, 2004, 351

125 Haipıng Hao, Guangı Wang and Janguo Sun, Ditug Metabolısm Reviews, 2005, 37, 215

126 V Wsol, L Skalova and B Szotakova, Current Drug Metabolısm. 2004, 5, 517

127 S S Adams, P Breloff and C G Mason, J Pharm Pharmacol, 1976, 28, 256

128 R D Carmer III, D E Patterson and J D Bunce, J Am Chem Soc , 1988, 110, 5959

129 G R Marshall and R D Ciamer, Trends Pharmacol Scı, 1988, 9, 285

130 A Golbraskh, D Bonchev and A Tropsha, J Chem Inf Comput $\mathrm{Scl}, 2001,41,147$

131 J V de Julıán-Ortız. C de G Alapont. I Rıos-Santamaıına, R Garcia-Domenech and J Gàlve7, J Mol Graphic Mod, 1998, 16, 14

132 A Kovatcheva, A Golbıaık, S Oloff, J Feng. W Zheng and A Tropsha, SAR and QSAR in Envionmental Reseaich, 2005, 16, 93

133 A Golbrakk and A Tropsha, J Chem Int Comput Sc1, 2003 43, 144

134 L Dinan R E Hormann and T Fupımoto, J Comput Alded Mol Der. 1999, 13, 185

135 W J Lambert and P G Timmer, Phurm Res, 1991, 8, 1944

136 Bezhan Chankvetadze, "Recent Trends in Enantioseparation of Chiral Drugs Methods and Prnciples in Medicinal Chemistry", (Molecular Bıology in Medicınal Chemıstiy), 2004, 21, pp 181210

137 Bezhan Chankvetadze and Jacques Ciommen, Journal of Pharmaceuncal and Bımedic al Analysıs, 2001, 27, 355

138 Hong-xı L1, Weı Lı and Xue-xın Gu, Нuaxue Yanjı, 2005, 16, 96

139 Robert J Pascoe, Alıcia G Peterson and Joe P Foley, Electrophorests, 2000, 21, 2033

140 S C Stınson, Chem Eng News, 1992, 46 